\title{
Measuring quality of sleep and autonomic nervous function in healthy Japanese women
}

\author{
This article was published in the following Dove Press journal: \\ Neuropsychiatric Disease and Treatment \\ 17 January 2014 \\ Number of times this article has been viewed
}

\author{
Miki Sato' \\ Yuko Yasuhara ${ }^{2}$ \\ Tetsuya Tanioka ${ }^{2}$ \\ Yukie Iwasa ${ }^{2}$ \\ Masafumi Miyake ${ }^{3}$ \\ Toshiyuki Yasui $^{2}$ \\ Masahito Tomotake ${ }^{2}$ \\ Haruo Kobayashi ${ }^{4}$ \\ Rozzano C Locsin ${ }^{5}$ \\ 'Department of Nursing, Faculty \\ of Nursing, Shikoku University, \\ ${ }^{2}$ Department of Nursing, Institute of \\ Health Biosciences, The University \\ of Tokushima Graduate School, \\ ${ }^{3}$ Tokushima Prefectural Minami Health \\ Care Center, Tokushima, ${ }^{4}$ Faculty of \\ Medical Welfare, Kawasaki University \\ of Medical Welfare, Kurashiki, Japan; \\ ${ }^{5}$ Christine E Lynn College of Nursing, \\ Florida Atlantic University, Boca \\ Raton, FL, USA
}

Correspondence: Miki Sato Department of Nursing, Faculty of Nursing, Shikoku University, I23-I, Aza, Ebisuno, Furukawa, Ojin-cho,

Tokushima 77I-I 192, Japan

$\mathrm{Tel}+8 \mid 886659237$

Fax +81886658037

Email msato@shikoku-u.ac.jp
Abstract: The purpose of this study was to determine the relationship between quality of sleep and autonomic nervous functioning in healthy adult Japanese women using three measures, namely, the Pittsburgh Sleep Quality Index (PSQI) for subjective assessment of sleep quality, actigraphy for objective assessment of sleep, and heart rate variability using high frequency and low frequency domains. Participants were 31 healthy women in their 20 s to 40 s who met the selection criteria, including having normal monthly menstrual periods. Participants were categorized as good or poor sleepers according to their PSQI score. Median correlation coefficients of activity count and high frequency were -0.62 (range -0.43 to -0.84 ) for good sleepers and -0.45 (range 0.003 to -0.64 ) for poor sleepers. Good sleepers showed a significantly higher correlation of activity count and high frequency $(Z=-2.11, P<0.05)$. Median correlation coefficients of activity count and low frequency/high frequency were 0.54 (range 0.29-0.73) for good sleepers and 0.41 (range $0.11-0.63$ ) for poor sleepers. The PSQI, actigraphy data, and heart rate variability results showed positive correlations between sleep time as measured by PSQI and duration of inactivity as measured by actigraphy $(r=0.446, P<0.05)$ and sleep time as measured by actigraphy $(r=0.377, P<0.05)$, and a negative correlation between sleep time as measured by PSQI and the correlation coefficients of activity count and high frequency ( $r=-0.460, P<0.01)$. These results support the finding that sleep-wake rhythms can be monitored efficiently with actigraphy, providing accurate data that can support the diagnosis of sleeping disorders. Furthermore, actigraphy data were associated with heart rate variability and PSQI findings, but only in subjects who were poor sleepers. Actigraphy is an accurate, efficient, rapid, and inexpensive test for determining objective and subjective sleeping problems, and can also be used in clinical tests for sleep assessment.

Keywords: Pittsburgh Sleep Quality Index, actigraph, heart rate variability, autonomic nervous system activity, women, screening method

\section{Introduction}

Sleep plays an important role in resting both the brain and the body. ${ }^{1}$ Polysomnography may be useful in order to accurately measure the quality and quantity of sleep.,3 Although the accuracy of this test is high, it is almost always conducted in a laboratory setting or requires hospital admission. In healthy people, actigraphy data have been found to have a high correlation with polysomnography, 4,5 indicating that it is possible to accurately assess sleep and wakefulness using an actigraph. This makes it possible to quantitatively measure sleep time with efficiency. ${ }^{6-8}$ Therefore, an actigraph ${ }^{9}$ is a useful and reliable instrument for gathering data that can diagnose sleep disorders relatively simply and noninvasively, particularly in healthy young people. 
While actigraphy and polysomnography are measured quantitatively, assessment of subjective sleep conditions is often difficult, although a questionnaire survey, ie, the Pittsburgh Sleep Quality Index (PSQI), ${ }^{10,11}$ has been found to be a reliable instrument that can easily and qualitatively measure sleep disorders. There have been two research studies using multiple variables such as "primary insomnia and sleep state misperception"12 and "smoking and subjective quality of sleep"13 and also using PSQI and polysomnography. Other research studies have focused on sleep disorders and quality of life, including both objective and subjective sleep disturbance patterns, using the PSQI and actigraphy. ${ }^{14-17}$ However, with PSQI and polysomnography, hospitalization is necessary to obtain data on a patient's sleep disorder. Altogether, these findings indicate that it may be possible to determine more objective disorders of sleep and autonomic nervous system function using a combination of subjective and objective assessments, rather than simply relying on sleeping time. ${ }^{18,19}$

With regard to sex as a research variable, there are data showing that menstrual cycles, pregnancy, and signs and symptoms of menopause have significant effects on sleep disorders. ${ }^{20}$ It is also known that insomnia is more frequent in women than in men in all age groups, and that women typically have more sleep-related complaints than men. ${ }^{21}$

The purpose of this study was to determine the relationship between quality of sleep and autonomic nervous system function in healthy adult Japanese women using three measurements, namely, the PSQI for subjective assessment of sleep quality, actigraphy for objective assessment of sleep, and heart rate variability using high frequency and low frequency domains.

\section{Materials and methods \\ Measurement items}

\section{Pittsburgh Sleep Quality Index}

Participants completed the Japanese version of the PSQI on the final day of the study. The PSQI is an internationally standardized scale, and the Japanese version (Cronbach's $\alpha=0.77)^{22}$ is reliable and appropriate for assessing lack of sleep and subjective quality of sleep. ${ }^{23,24}$ A PSQI score of $\geq 6.0$ is used as the cutoff point to determine the risk of poor sleep quality. ${ }^{25}$

\section{Actigraphy}

Actigraphy is a measurement procedure that is used to assess the balance between waking time and sleeping time, and the conditions of sleep disturbance. ${ }^{26}$ In this study, a portable micro mini-type actigraph (Ambulatory Monitoring, Inc, Ardsley, NY, USA) was attached to each participant's nondominant arm for 3 days ( 72 hours) starting at 6 pm on day 1 until the finish time on day 3. Objective sleep time was obtained from the actigraph records. The actigraph was worn on the wrist like a watch and electronically measured the number of movements exceeding $0.01 \mathrm{~g}$ (gravitational force per minute of recording). Sleep or wake time was judged by activity count on the actigraph. The time during which the participants were wearing the actigraph was divided into "up" (daytime activity) intervals, defined as the period of time participants reported being out of bed, and "down" (sleep) intervals, defined as the period during which participants were in bed.

The following terms and abbreviations were used for the actigraph measurement items: Duration (time [minutes] from the start to the end of the "down" interval [sleep time]); $\mathrm{W}_{\text {min }}$ (the total time [minutes] of wake time); $\mathrm{S}_{\text {min }}$ (minutes scored as "asleep" [sleep + light sleep]); and PSLP (percentage of time spent sleeping [minutes]). $\mathrm{S}_{\min }$ was converted into hours (converted $\mathrm{S}_{\min }$ ) to match the sleep time described on the PSQI.

\section{Heart rate variability}

Heart rate variability is an efficient noninvasive method used to investigate autonomic nervous system function and cardiovascular control while awake or during sleep. In this study, electrodes were placed at strategic locations on the chest and recording was done via a portable Holter electrocardiographic monitor for 24 hours. The heart rate variability results included the low frequency component $(0.04-0.15 \mathrm{~Hz})$ and the high frequency component $(0.15-0.50 \mathrm{~Hz})$, as extracted by power-spectrum density. The high frequency component also served as an indicator of parasympathetic nervous system activity. Low frequency/high frequency indicates sympathetic nervous system activity.

\section{Participants and data collection period}

Participants comprised 31 volunteer adult Japanese women aged in their 20s to 40 s who described themselves as being healthy. Volunteers were included in the study if they met the following criteria: a normal monthly menstrual cycle, no menopausal symptoms, a normal body mass index (range 17.5-25.3), no eating disorder, and on a regular diet. Prospective volunteers working on rotating or night schedules, and those who were pregnant or menopausal were excluded from the study. The subjects were instructed not to consume alcohol during the study period. The data were collected from June 2012 to August 2013. 


\section{Analytical methods}

The researcher explained the procedures for data collection to all subjects who met the selection criteria. In order to obtain accurate measurements, participants were instructed on how to use the actigraphic and electrocardiographic devices. These were all done by the researchers (MS, YY, and TT). Actigraph and heart rate variability data were analyzed using a dedicated analyzer, and the results were recorded graphically, enabling visual assessment. Such visual representation provided clear reliable data. The data obtained from the actigraph were analyzed using AW2 software (Ambulatory Monitoring, Inc). Time series data for the interbeat interval were formalized from the FM180 electrocardiograph (Fukuda Denshi Co, Ltd, Tokyo, Japan) using Holter software (Fukuda Denshi Co, Ltd). Heart rate variability was analyzed using the Mem Calc/CHIRAM procedure (GMS Co, Tokyo, Japan).

Sleep quality was assessed using the PSQI. The participants were divided into two groups, ie, good sleepers (PSQI score $<6$ ) and poor sleepers (those at risk of poor sleep quality, ie, PSQI score $\geq 6$ ). The activity count was matched with the heart rate variability data produced over 5 -minute intervals. Differences between the two groups with regard to actigraph and heart rate variability data were analyzed using the Mann-Whitney $U$ statistical test. Correlations between activity count and parasympathetic and sympathetic nervous system activity were analyzed using Pearson's product-moment correlation coefficient. PSQI score and other items of the actigraph and heart rate variability data were analyzed using Spearman's product-moment correlation coefficient statistic. Differences between average values of parasympathetic and sympathetic nervous system activity during the daytime and while asleep were assessed using an unpaired $t$-test statistic. The statistical analysis was carried out using Statistical Package for the Social Sciences version 18 software (PASW Statistics for Windows, SPSS Inc, Chicago, IL, USA). Statistical significance was set at $P<0.05$.

\section{Ethical considerations}

The data were managed according to the Private Information Protection Law, with approval from the Tokushima University Hospital ethics board (approval number 1558). Participants were assured that their personal information would be protected, reported in aggregate, and used only for research purposes. The purpose and methods used in the study were explained to all participants, with informed consent obtained thereafter.

\section{Results \\ Clinical and demographic characteristics of subjects}

The participants comprised 14 university students and 17 light-duty workers (clerks); 18 were single and 13 were married (Table 1). All participants had regular monthly menstrual cycles. The median age of the participants was 32 (range 20-48) years. The median PSQI score was 5 (range $2-15)$ points. Among the 14 participants who scored above the cutoff PSQI score of 6 , four were in their 20 s, six were in their 30s, and four were in their 40s. The median body mass index was 20.6 (range 17.5-25.3) $\mathrm{kg} / \mathrm{m}^{2}$. The median Duration judged by AW2 was 382 (range 256-589) minutes, the converted $\mathrm{S}_{\min }$ was 6 (range 4-10) hours, $\mathrm{W}_{\min }$ was 23 (range 7-79) minutes, and $\mathrm{S}_{\min }$ was 365 (range 233-538) minutes. The median PSLP as measured by actigraphy was $92.20 \%$ (range $79.19 \%-98.12 \%$ ). The median activity count and high frequency correlation coefficient was -0.60 (range 0.003 to -0.84 ), and the median activity count and low frequency/high frequency correlation coefficient was 0.50 (range $0.11-0.73$ ). In addition, the mean value for

Table I Summary of all participants' measured item values $(n=31)$

\begin{tabular}{llll}
\hline Measured items & Median (range) & Measured items & Median (range) \\
\hline PSQI score (points) & $5(2-15)$ & & $-0.60(-0.84-0.003)$ \\
BMI $\left(\mathrm{kg} / \mathrm{m}^{2}\right)$ & $20.6(17.5-25.3)$ & Correlation coefficient of AC and HF $(\mathrm{r})$ & $0.50(0.1 \mathrm{I}-0.73)$ \\
Duration $(\mathrm{min})$ & $382(256-589)$ & Correlation coefficient of AC and LF/HF $(\mathrm{r})$ & $374.10(97.18-1,772.19)$ \\
Converted S $_{\min }(\mathrm{h})$ & $6(4-10)$ & Mean value of HF in down interval $\left(\mathrm{msec}^{2}\right)$ & $175.40(42.45-674.78)$ \\
$\mathrm{W}_{\text {min }}(\mathrm{min})$ & $23(7-79)$ & Mean value of HF in up interval $\left(\mathrm{msec}^{2}\right)$ & $2.20(0.91-5.36)$ \\
$\mathrm{S}_{\text {min }}(\min )$ & $365(233-538)$ & Mean value of LF/HF in down interval (ratio) & $5.00(2.45-\mathrm{II} .65)$ \\
PSLP $(\%)$ & $92.20(79.19-98.12)$ & Mean value of LF/HF in up interval (ratio) & \\
\hline
\end{tabular}

Notes: Participants were 14 university students and 17 light-duty workers (clerks); 18 were single and I 3 were married. All had regular menstrual cycles. Among the 14 participants who scored above the cutoff PSQI score $(£ 6)$, four were in their 20s, six were in their 30s, and four were in their 40 s.

Abbreviations: PSQI, Pittsburgh Sleep Quality Index; BMI, body mass index; Duration, time (min) from the start to the end of the "down" interval; Converted $\mathrm{S}_{\text {min }}$, $\mathrm{S}_{\text {min }}$ converted to hours to match $\mathrm{S}_{\text {time }} ; \mathrm{W}_{\text {min }}$, number of minutes scored; $\mathrm{S}_{\text {min }}$, number of minutes scored as sleep; PSLP, percentage of minutes of sleep; AC, activity count; HF, high frequency; LF, low frequency; h, hours; min, minutes. 
high frequency during a "down" interval was 374.10 (range 97.18-1,772.19) $\mathrm{msec}^{2}$ and that during the "up" interval was 175.40 (range 42.45-674.78) $\mathrm{msec}^{2}$; the mean value of low frequency/high frequency during the "down" interval was 2.20 (range 0.91-5.36) and that during the "up" interval was 5.00 (range $2.45-11.65$ ).

\section{Characteristics of sleep quality}

Sleep quality was assessed using the PSQI; 17 participants whose scores were below the cutoff point were classified as good sleepers and 14 participants whose scores were above the cutoff point were classified as poor sleepers (Table 2). Significant differences were observed in sleep time described on the PSQI, the correlation coefficient of activity count and high frequency, and the correlation coefficient of activity count and low frequency/high frequency. The median sleep time described on the PSQI was 7 (range 5-9) hours for good sleepers and 6 (range 4-7) hours for poor sleepers. Sleep time described on the PSQI in the good sleeper group was significantly longer $(Z=-2.29, P<0.05)$. The median activity count and high frequency correlation coefficient in the good sleeper group was -0.62 (range -0.43 to -0.84 ) and that in the poor sleeper group was -0.45 (range -0.64 to 0.003 ); there was a significant negative correlation between activity count and high frequency in the good sleepers $(Z=-2.11, P<0.05)$. The median activity count and low frequency/high frequency correlation coefficients were 0.54 (range 0.29-0.73) and 0.41 (range 0.11-0.63) for the good and poor sleepers, respectively. The correlation was significantly strong between activity count and low frequency/high frequency in the good sleepers $(Z=-2.53$,
$P<0.05)$. No significant difference was observed for any of the other items.

\section{Sleep time as measured by PSQI, actigraph, and autonomic nervous function}

Sleep time as described on the PSQI for the previous month, actigraphy data, and heart rate variability data were analyzed (Table 3). Sleep time as described on the PSQI was recognized as having a significant positive correlation with Duration $(r=0.446, P<0.05)$ and converted $\mathrm{S}_{\text {min }}(r=0.465$, $P<0.01)$, a positive correlation with $\mathrm{S}_{\min }(r=0.377, P<0.05)$, and a negative correlation with the activity count and high frequency correlation coefficient $(r=-0.460, P<0.01)$. Duration was found to have a positive correlation with the converted $\mathrm{S}_{\text {min }}(r=0.961, P<0.01)$ and $\mathrm{S}_{\min }(r=0.940, P<0.01)$, and $\mathrm{a}$ negative correlation with activity count $(r=-0.499, P<0.01)$ and the average of the low frequency/high frequency value ( $r=-0.366, P<0.05)$.

Converted $\mathrm{S}_{\min }$ was observed to have a positive correlation with $\mathrm{S}_{\min }(r=0.937, P<0.01)$ and a negative correlation with activity count $(r=-0.477, P<0.01)$. $\mathrm{W}_{\text {min }}$ had a negative correlation with PSLP ( $r=-0.955$, $P<0.01)$. In contrast, $\mathrm{S}_{\min }$ had a positive correlation with PSLP $(r=0.404, P<0.05)$ and a negative correlation with activity count $(r=-0.531, P<0.01)$. There was a negative correlation between the activity count and high frequency correlation coefficient and that for activity count and low frequency/high frequency $(r=-0.371, P<0.05)$. There was also a negative correlation between the mean value for

Table 2 Characteristics of the measured items by sleep quality

\begin{tabular}{|c|c|c|c|c|}
\hline \multirow[t]{2}{*}{ Measured items } & \multirow{2}{*}{$\begin{array}{l}\text { Good sleepers }(n=17) \\
\text { Median (range) }\end{array}$} & \multirow{2}{*}{$\begin{array}{l}\text { Poor sleepers }(n=\mid 4) \\
\text { Median (range) }\end{array}$} & \multirow[t]{2}{*}{$\mathbf{Z}$} & \multirow[t]{2}{*}{$P$} \\
\hline & & & & \\
\hline $\mathrm{S}_{\text {time }}$ on PSQI (h) & $7(5-9)$ & $6(4-7)$ & -2.29 & $*$ \\
\hline Duration (min) & $409(269-589)$ & $376(256-507)$ & -1.17 & NS \\
\hline Converted $\mathrm{S}_{\min }(\mathrm{h})$ & $7(4-10)$ & $6(4-8)$ & -1.79 & NS \\
\hline$W_{\min }(\min )$ & $26.5(7-79)$ & $23(13-68)$ & -0.08 & NS \\
\hline $\mathrm{S}_{\min }(\min )$ & $389(238-538)$ & $348(233-492)$ & -1.15 & NS \\
\hline PSLP (\%) & $92.70(79.19-98.12)$ & $92.24(82.20-97.43)$ & -0.18 & NS \\
\hline Correlation coefficient of AC vs HF (r) & $-0.62(-0.43$ to -0.84$)$ & $-0.45(-0.64$ to 0.003$)$ & -2.11 & $*$ \\
\hline Correlation coefficient of AC vs LF/HF (r) & $0.54(0.29-0.73)$ & $0.4 \mathrm{I}(0.1 \mathrm{I}-0.63)$ & -2.53 & $*$ \\
\hline $\mathrm{BMI}\left(\mathrm{kg} / \mathrm{m}^{2}\right)$ & $21.1(17.7-25.3)$ & $21.0(17.5-25.3)$ & -0.33 & NS \\
\hline$A C$ (count) & I48.53 (99.4-177.24) & I56.16 (83.49-194.48) & -0.85 & NS \\
\hline Mean value of $\mathrm{HF}\left(\mathrm{msec}^{2}\right)$ & 275.7I (94.9I-950.38) & 147.70 (76.65-753.16) & -1.08 & NS \\
\hline Mean value of LF/HF (ratio) & $4.11(1.87-8.97)$ & $4.91(2.34-6.09)$ & -0.72 & NS \\
\hline
\end{tabular}

Notes: Mann-Whitney $U$ test. $* P<0.05$; NS: not significant. $S_{\text {time }}$ is subjective sleep time described on PSQI (h).

Abbreviations: PSQI, Pittsburgh Sleep Quality Index; BMI, body mass index; Duration, time ( $\mathrm{min}$ ) from the start to the end of the "down"; Converted $\mathrm{S}_{\min }$, $\mathrm{S}_{\min }$ converted to hours to match $\mathrm{S}_{\text {time }} ; \mathrm{W}_{\text {min }}$, number of minutes scored as awake; $\mathrm{S}_{\text {min }}$, number of minutes scored; PSLP, percentage of minutes of sleep; $A C$, activity count; $\mathrm{HF}$, high frequency; LF, low frequency; h, hours; min, minutes; vs, versus. 


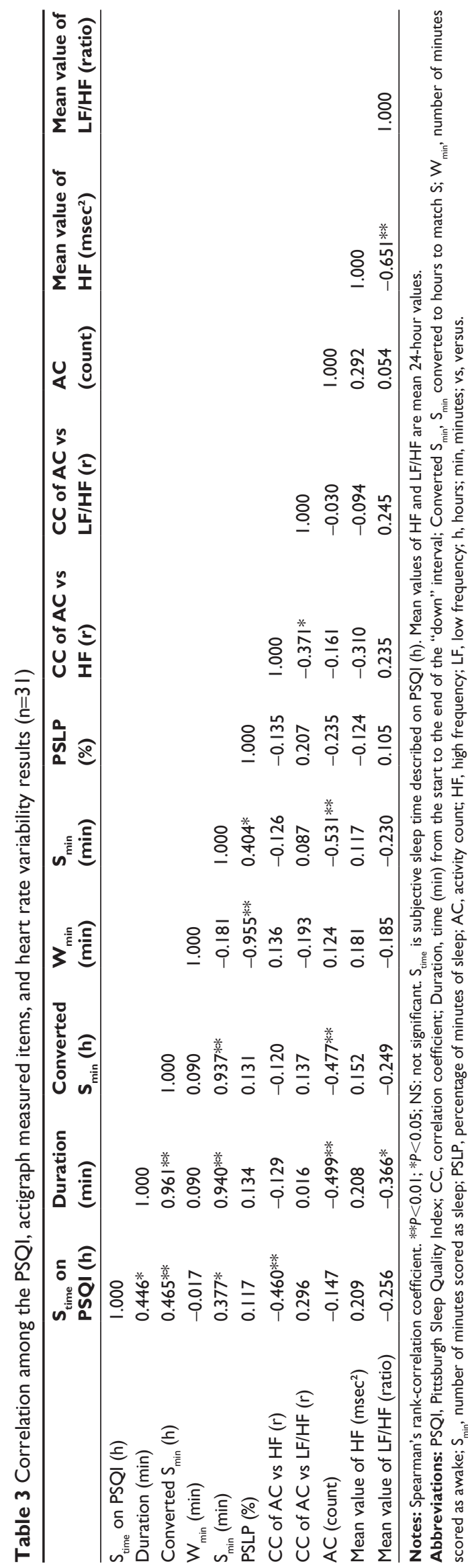

high frequency and that for low frequency/high frequency $(r=-0.651, P<0.01)$.

\section{Discussion}

Previous studies ${ }^{27,28}$ have indicated that subjective sleep time is associated with a risk of developing lifestyle-related diseases, although some of these studies ${ }^{29-31}$ used objective sleep data as well. Compounding subjective sleep data with objective sleep data provides a more accurate evaluation of sleep state as a risk of lifestyle-related disease. Therefore, it is important to compare and evaluate the influence of subjective and objective sleep time in order to correctly determine the risk of developing lifestyle-related diseases and autonomic nervous functioning. In the present study, subjective sleep time (measured by the PSQI) and objective sleep time $\left(\mathrm{S}_{\min }\right)$ were used as variables.

Subjects with an average sleep time of 6-8 hours are generally regarded as having the lowest risk for diabetes mellitus and obesity. ${ }^{27,28}$ However, in this study of 31 participants, 14 had PSQI scores above the cutoff value of 6, indicating poor subjective sleep quality. Comparison of good sleepers and poor sleepers showed that although sleep time as measured by PSQI was significantly longer in good sleepers, no significant differences in Duration and $\mathrm{S}_{\min }$ were observed between the two groups.

Differences between subjective sleep time and objective data have been reported, ${ }^{29,30}$ and personal emotions are known to affect subjective satisfaction with sleep. The correlations between activity count and high frequency and between activity count and low frequency/high frequency were significantly weaker in the poor sleeper group. Therefore, it is useful when considering patient education or therapeutic efficacy monitoring for poor sleepers that three measurements are available; ie, the PSQI, actigraphy, and heart rate variability.

Furthermore, it was assumed that there was a negative correlation between activity count and high frequency over 24 hours, which is an indication of a healthy representation of sleep-wake rhythm. ${ }^{31,32}$ There was a positive correlation between activity count and low frequency/high frequency, indicating that for women aged 20-40 years with a normal body mass index, activity count obtained by actigraphy can be used as an indicator for assessment of autonomic nervous function. There was a negative correlation between the average value of high frequency and that of low frequency/ high frequency, and this was presumed to be the result of antagonistic double innervation of autonomic nerves. ${ }^{33,34}$ This finding suggests the possibility of determining the status of sleep and autonomic nervous function by assessing the correlation coefficient of activity count and high frequency or 
low frequency/high frequency. ${ }^{32,35}$ The fact that there were positive correlations between sleep time as measured by PSQI and Duration and $\mathrm{S}_{\min }$ is consistent with previous research on PSQI and actigraphy.

On the PSQI, poor sleepers were recognized as having a significantly short subjective sleep time. In addition, considering that the correlation coefficient of activity count versus high frequency and that of activity count versus low frequency/high frequency are significantly lower in poor sleepers compared with good sleepers, it was considered possible to detect poor subjective sleep status and low autonomic nervous function by combining actigraphy and heart rate variability analysis. In addition, because a significant negative correlation was observed between sleep time as measured by PSQI and the correlation coefficient of activity count versus high frequency, individuals with a short sleep time as measured by PSQI were thought to have a low correlation coefficient between activity count and high frequency, indicating low parasympathetic function.

In a population-based sample of middle-aged adults, sleep time as measured by PSQI is moderately correlated with $\mathrm{S}_{\min }$, but is biased by systematic over-reporting. The true associations between sleep duration and health may differ from associations between self-reported sleep and health. ${ }^{36}$ Participants with poor sleep quality on the PSQI can be examined in everyday settings (normal life, including work) by assessing the sleep-wake rhythm condition using a combination of an actigraph and heart rate variability analysis, and without the use of complicated diagnostic equipment such as polysomnography, a procedure that requires hospitalization in order to collect data. Also, in the case of the treatment of sleep disorders, therapeutic results used in the testing methods by this research can be effectively shown to a patient.

In this study, because the participants were young (20s to $40 \mathrm{~s}$ ), and this age group typically does not have problems with falling or staying asleep, few difficult cases of getting to sleep and arousal during sleep were identified. However, in order to assess and diagnose the sleep condition and determine the autonomic nervous system disorder for the participants whose $\mathrm{W}_{\text {min }}$, or arousal during sleep, was long, it is important to discuss both Duration and actual $\mathrm{S}_{\min }$ with the patient, simply because even if Duration is between 6 and 8 hours, the actual $\mathrm{S}_{\min }$ is shorter. In such cases, where there was a negative correlation between sleep time as described on the PSQI and the correlation coefficient of activity count and high frequency, and where sleep time as described on the PSQI was long (6-8 hours), it was presumed that the negative correlation between activity count and high frequency was strong. It was considered possible to predict autonomic nervous function to a certain extent by assessing sleep time and sleep quality as described on the PSQI and the measured actigraph results. Chronic sleep deprivation is associated with cardiovascular events. It causes an autonomic imbalance and decreases intracellular magnesium levels, which may be associated with chronic sleep deprivation-induced cardiovascular events. ${ }^{37}$ Therefore, it was considered that there is a need to study further factors which may potentially influence these sleep-wake conditions.

There was a significant negative correlation between activity count, Duration, converted $\mathrm{S}_{\min }$, and $\mathrm{S}_{\min }$. If the activity count is large, Duration, converted $\mathrm{S}_{\min }$, and $\mathrm{S}_{\min }$ are short. Therefore, it is recommended that results of the PSQI, actigraph, and heart rate variability be considered when undertaking a sleep quality study to establish the diagnosis. In the case report of a man with a sleep disorder who was examined with a combination of actigraphy and heart rate variability analysis, ${ }^{33,38}$ the correlation between activity count and high frequency or low frequency/high frequency was weak. In addition, in cases of elderly patients with diabetes mellitus, ${ }^{34,39}$ sleep time was long and the correlation between activity count and high frequency or low frequency/high frequency was weak as well. These findings suggest that it is possible to predict changes in autonomic nervous function due to disease by assessing these factors using a combination of actigraphy and heart rate variability analysis.

\section{Limitations}

The participants in this research had a body mass index within the normal range. ${ }^{35,40}$ However, high frequency and low frequency/high frequency can be affected by activity, diet, and stress. These data may fluctuate within individuals. ${ }^{18,34}$ Although standards of high frequency and low frequency/high frequency by age group have been provided, they vary between individuals..$^{39,41}$ The power of high frequency components decreases with advancing aging. ${ }^{40,42,43}$ Therefore, it is important to increase the number of participants in future studies, and test for differences between age groups.

Complicated calculations were required for high frequency and low frequency/high frequency. However, the development of simple calculation software will be helpful for the diagnosis of sleep quality conditions and abnormalities in autonomic nervous function. It is necessary to increase the number of participants and move further ahead with research 
on the correlations among sleep quality, activity count, and autonomic nervous function.

The participants in this research were healthy women in their $20 \mathrm{~s}$ to $40 \mathrm{~s}$, and all were Japanese. Therefore, there are limitations when applying the results of this research to unhealthy men and women, and to other ethnic/racial and minority groups. In addition, the menstrual cycle of the participants was not taken into consideration. It is important to clarify the standard values necessary to detect sleep condition and autonomic nervous function by taking the menstrual cycle into consideration, and increasing the number of samples (including consideration of sex, particularly for men).

The criteria for patient selection did not consider coffee intake, which is known to influence sleep-wake rhythms. The current study was conducted without restriction of coffee intake, allowing a normal daily consumption of coffee. Finally, family history of neurologic disorders was another factor not considered in this study.

\section{Conclusion}

The aim of this study was to determine the relationship between quality of sleep and autonomic nervous system functioning using three measurements, ie, the PSQI, actigraphy, and heart rate variability. Actigraphy data were associated with heart rate variability and PSQI findings, but only in subjects who were poor sleepers. This affirms the value of actigraphy as a rapid, efficient, and inexpensive means of assessing sleep disorders. Actigraphy and PSQI are significant clinical tests which can be useful to supplement other techniques of sleep assessment.

\section{Acknowledgments}

We would like to express our deep gratitude to the participants of this study, our family members, and members of Professor Tanioka's laboratory. In particular, we wish to thank the following clinicians for their participation in this study: Dr Seizo Kinosita, MD, PhD and Dr Masatoshi Masuda, MD, PhD (Kinosita Hospital); Dr Hiroshi Shimizu, MD, PhD (Toyo Hospital); and Dr Kazuyo Harada, MD, PhD (Harada Clinic).

\section{Disclosure}

All of the coauthors declare that they have no direct conflict of interest or grant support that is directly related to the content of the study.

\section{References}

1. Paller KA, Voss JL. Memory reactivation and consolidation during sleep. Learn Mem. 2004;11(6):664-670.
2. Banhiran W, Assanasen P, Metheetrairut C, Chotinaiwattarakul W. Health-related quality of life in Thai patients with obstructive sleep disordered breathing. J Med Assoc Thai. 2013;96(2):209-216.

3. Appelhans BM, Janssen I, Cursio JF, et al. Sleep duration and weight change in midlife women: the SWAN sleep study. Obesity (Silver Spring). 2013;21(1):77-84.

4. Sadeh A, Sharkey KM, Carskadon MA. Activity-based sleep-wake identification: an empirical test of methodological issues. Sleep. 1994;17(3): 201-207.

5. Jean-Louis G, Kripke DF, Mason WJ, Elliott JA, Youngstedt SD. Sleep estimation from wrist movement quantified by different actigraphic modalities. J Neurosci Methods. 2001;105(2):185-191.

6. Camargos EF, Louzada FM, Nóbrega OT. Wrist actigraphy for measuring sleep in intervention studies with Alzheimer's disease patients: application, usefulness, and challenges. Sleep Med Rev. 2013;17(6): 475-488.

7. Arora T, Broglia E, Pushpakumar D, Lodhi T, Taheri S. An investigation into the strength of the association and agreement levels between subjective and objective sleep duration in adolescents. PLoS One. 2013;8(8):e72406.

8. Williams JM, Kay DB, Rowe M, McCrae CS. Sleep discrepancy, sleep complaint, and poor sleep among older adults. J Gerontol B Psychol Sci Soc Sci. 2013;68(5):712-720.

9. Wood AC, Kuntsi J, Asherson P, Saudino KJ. Actigraph data are reliable, with functional reliability increasing with aggregation. Behav Res Methods. 2008;40(3):873-878.

10. Huang Y, Mai W, Hu Y, et al. Poor sleep quality, stress status, and sympathetic nervous system activation in nondipping hypertension. Blood Press Monit. 2011;16(3):117-123.

11. Kung YY, Yang CC, Chiu JH, Kuo TB. The relationship of subjective sleep quality and cardiac autonomic nervous system in postmenopausal women with insomnia under auricular acupressure. Menopause. 2011;18(6):638-645.

12. Dittoni S, Mazza M, Losurdo A, et al. Psychological functioning measures in patients with primary insomnia and sleep state misperception. Acta Neurol Scand. 2013;128(1):54-60.

13. Jaehne A, Unbehaun T, Feige B, Lutz UC, Batra A, Riemann D. How smoking affects sleep: a polysomnographical analysis. Sleep Med. 2012;13(10):1286-1292.

14. Dean GE, Redeker NS, Wang YJ, et al. Sleep, mood, and quality of life in patients receiving treatment for lung cancer. Oncol Nurs Forum. 2013;40(5):441-451.

15. Berger AM, Kuhn BR, Farr LA, et al. Behavioral therapy intervention trial to improve sleep quality and cancer-related fatigue. Psychooncology. 2009;18(6):634-646.

16. Redeker NS, Hilkert R. Sleep and quality of life in stable heart failure. J Card Fail. 2005;11(9):700-704.

17. Hamera E, Brown C, Goetz J. Objective and subjective sleep disturbances in individuals with psychiatric disabilities. Issues Ment Health Nurs. 2013;34(2):110-116.

18. Mezick EJ, Matthews KA, Hall MH, Richard Jennings J, Kamarck TW. Sleep duration and cardiovascular responses to stress in undergraduate men. Psychophysiology. 2014;51(1):88-96.

19. Burgess HJ, Trinder J, Kim Y. Cardiac autonomic nervous system activity during presleep wakefulness and stage 2 NREM sleep. J Sleep Res. 1999;8(2):113-122.

20. Krishnan V, Collop NA. Gender differences in sleep disorders. Curr Opin Pulm Med. 2006;12(6):383-389.

21. Tamanna S, Geraci SA. Major sleep disorders among women: (women's health series). South Med J. 2013;106(8):470-478.

22. Doi Y, Minowa M, Uchiyama M, et al. Psychometric assessment of subjective sleep quality using the Japanese version of the Pittsburgh Sleep Quality Index (PSQI-J) in psychiatric disordered and control subjects. Psychiatry Res. 2000;97(2-3):165-172.

23. Shochat T, Tzischinsky O, Oksenberg A, Peled R. Validation of the Pittsburgh Sleep Quality Index Hebrew translation (PSQI-H) in a sleep clinic sample. Isr Med Assoc J. 2007;9(12):853-856. 
24. Backhaus J, Junghanns K, Broocks A, Riemann D, Hohagen F. Testretest reliability and validity of the Pittsburgh Sleep Quality Index in primary insomnia. J Psychosom Res. 2002;53(3):737-740.

25. Buysse DJ, Reynolds CF 3rd, Monk TH, Berman SR, Kupfer DJ. The Pittsburgh Sleep Quality Index: a new instrument for psychiatric practice and research. Psychiatry Res. 1989;28(2):193-213.

26. Chung GS, Choi BH, Jeong DU, Park KS. Noninvasive heart rate variability analysis using loadcell-installed bed during sleep. Conf Proc IEEE Eng Med Biol Soc. 2007;2007:2357-2360.

27. Gottlieb DJ, Punjabi NM, Newman AB, et al. Association of sleep time with diabetes mellitus and impaired glucose tolerance. Arch Intern Med. 2005;165(8):863-867.

28. Hasler G, Buysse DJ, Klaghofer R, et al. The association between short sleep duration and obesity in young adults: a 13-year prospective study. Sleep. 2004;27(4):661-666.

29. Bruyneel M, Sanida C, Art G, et al. Sleep efficiency during sleep studies: results of a prospective study comparing home-based and in-hospital polysomnography. J Sleep Res. 2011;20(1 Pt 2):201-206.

30. Yoshiike N, Seino F, Tajima S, et al. Twenty-year changes in the prevalence of overweight in Japanese adults: the National Nutrition Survey 1976-1995. Obes Rev. 2002;3(3):183-190.

31. Sato M, Yasuhara Y, Tanioka T, et al. Changes before and after improvement of subjective sleep state of a man diagnosed with pre-diabetes and sleep disorder. Health. 2013;5(3A):504-511.

32. Sato M, Yasuhara Y, Tanioka T, et al. The relationship between sleep condition and autonomic nervous function in women in their 70s with type 2 diabetes mellitus. Health. 2013;5(11):1875-1883.

33. Lee KH, Yoon K, Ha M, Park J, Cho SH, Kang D. Heart rate variability and urinary catecholamines from job stress in Korean male manufacturing workers according to work seniority. Ind Health. 2010;48(3):331-338.
34. Orsila R, Virtanen M, Luukkaala T, et al. Perceived mental stress and reactions in heart rate variability - a pilot study among employees of an electronics company. Int J Occup Saf Ergon. 2008;14(3):275-283.

35. Yoshiike N, Kaneda F, Takimoto H. Epidemiology of obesity and public health strategies for its control in Japan. Asia Pac J Clin Nutr. 2002; 11 Suppl 8:S727-S731.

36. Lauderdale DS, Knutson KL, Yan LL, Liu K, Rathouz PJ. Self-reported and measured sleep duration: how similar are they? Epidemiology. 2008;19(6):838-845.

37. Takase B, Akima T, Satomura K, et al. Effects of chronic sleep deprivation on autonomic activity by examining heart rate variability, plasma catecholamine, and intracellular magnesium levels. Biomed Pharmacother. 2004;58 Suppl 1:S35-S39.

38. Crasset V, Mezzetti S, Antoine M, Linkowski P, Degaute JP, van de Borne P. Effects of aging and cardiac denervation on heart rate variability during sleep. Circulation. 2001;103(1):84-88.

39. Abhishekh HA, Nisarga P, Kisan R, et al. Influence of age and gender on autonomic regulation of heart. J Clin Monit Comput. 2013;27(3):259-264.

40. Piccirillo G, Fimognari FL, Viola E, Marigliano V. Age-adjusted normal confidence intervals for heart rate variability in healthy subjects during head-up tilt. Int J Cardiol. 1995;50(2):117-124.

41. Montano N, Porta A, Cogliati C, et al. Heart rate variability explored in the frequency domain: a tool to investigate the link between heart and behavior. Neurosci Biobehav Rev. 2009;33(2):71-80.

42. Perini R, Veicsteinas A. Heart rate variability and autonomic activity at rest and during exercise in various physiological conditions. Eur $J$ Appl Physiol. 2003;90(3-4):317-325.

43. Martin JS, Hébert M, Ledoux E, Gaudreault M, Laberge L. Relationship of chronotype to sleep, light exposure, and work-related fatigue in student workers. Chronobiol Int. 2012;29(3):295-304.
Neuropsychiatric Disease and Treatment

\section{Publish your work in this journal}

Neuropsychiatric Disease and Treatment is an international, peerreviewed journal of clinical therapeutics and pharmacology focusing on concise rapid reporting of clinical or pre-clinical studies on a range of neuropsychiatric and neurological disorders. This journal is indexed on PubMed Central, the 'PsycINFO' database and CAS.

\section{Dovepress}

The manuscript management system is completely online and includes a very quick and fair peer-review system, which is all easy to use. Visit http://www.dovepress.com/testimonials.php to read real quotes from published authors.

\footnotetext{
Submit your manuscript here: http://www.dovepress.com/neuropsychiatric-disease-and-treatment-journal
} 